\title{
The past is everywhere
}

\section{Drowned in the Nile}

The pharaoh had been able to look at his reflection in the Nile for thousands of years. But now his face was sawn off, raised, and removed. One by one, stone blocks from the colossal statues were removed from the site. Was this because of a desire to obliterate the memory of a powerful absolute ruler? Was it an example of iconoclasm, in which the face of the god was mutilated? Were the sculptures going to be moved to a museum in the West, like so many other monuments and finds from Ancient Egypt? Or was it quite simply a case of vandalism?

The cliff temples of Abu Simbel were erected at the initiative of Pharaoh Ramses II, whose mummy is now exhibited in Cairo. The temples were carved directly out of the cliffs in the years around 1260 вСE. The great temple fronted by the four gigantic statues of Ramses II was a homage to the pharaoh himself as divine, a homage to the gods Amun-Ra, Ra-Horakhty, and Ptah, a memorial of the Battle of Kadesh, and a marker of Egyptian mastery of the Nubian border region. Twice a year, the rays of the rising sun would penetrate to the statues in the furthest depths of the temple. The nearby smaller temple was a homage to Ramses himself, his favourite wife Nefertari, and the goddess Hathor (MacQuitty 1965; Desroches Noblecourt 2007: 116ff).

But the temples of Abu Simbel were soon forgotten and covered by sand. The colossal statues were rediscovered in 1813 by the Orientalist Johann Ludwig Burckhardt, who had converted to Islam and was known in Egypt as Sheik Ibrahim ibn Abdullah; he also rediscovered Petra in Jordan. The Egyptologist Giovanni Battista Belzoni, who was hunting for antiquities along the Nile on behalf of Consul Henry Salt, heard about Abu Simbel from Burckhardt. In adventurous circumstances and in rivalry with French colleagues, Belzoni had the great temple cleared of so much 
sand that he was able to access its interior in 1817. After that, the temple was emptied of a few moveable items and documented. Several scientific expeditions followed during the nineteenth century (Fagan 1975: 124ff, 143ff, 172ff).

In an Egypt under British rule, a dam was erected at Aswan in 1898-1902 to regulate the Nile. The dam was subsequently raised several times. As a result of the higher water level, the temples along the river were flooded every year; but the cliff temples of Abu Simbel, with their relatively elevated location, were not. By contrast, the island of Philae, with a temple dedicated to the goddess Isis, came under water for 9 of the 12 months of the year. And in the decades following the establishment of the dam, there were several archaeological campaigns that involved investigations of threatened ancient monuments in Nubia, the gold country that is divided between Egypt and the Sudan.

The coup d'état or revolution of the Egyptian "Free Officers" in 1952 was aimed against the monarchy and the continued British influence. It was supported by the United States of America (US), the new post-war superpower. Plans were soon made to erect a new and higher Aswan dam, the Aswan High Dam, which would regulate the Nile and produce electricity, thereby contributing to the industrialisation of the country. The Aswan High Dam became a symbol of Egypt's national independence and modernisation, but its implementation was to have far-reaching consequences. After trying in vain to get the US to finance the project, President Gamal Abdel Nasser decided in 1956 to nationalise the strategically important Suez Canal so as to obtain the necessary funds. However, the subsequent Suez Crisis, in which the two old rivals and colonial powers Britain and France tried - along with Israel - to take control of the canal, clarified the new post-war world order. The US and the Soviet Union (USSR) forced the attackers to withdraw (Laron 2013).

The Aswan High Dam was not only to have political consequences. The dam would also create a lake, Lake Nasser (Lake Nubia in Sudan), which would drown the temples at Abu Simbel as well as many other traces of Ancient Nubia. The water might dissolve the sandstone of the temples. Consequently, the modernisation of Egypt threatened to drown and destroy Nubia's heritage. After millennia, the mighty pharaoh's monuments would cease to exist. Something that had been intended to be permanent would disappear. Abu Simbel risked becoming an icon of impermanence.

The modernisation involving the construction of the Aswan High Dam was carried out from 1960 to 1970 . But as early as 
the mid-1950s, several years before the actual construction work, intensive documentation of the temples had been initiated, a project that included photogrammetry. Soon, however, the ambition was extended to salvaging as much as possible with international assistance. Both Egypt and the Sudan approached the United Nations Educational, Scientific and Cultural Organization (UNESCO) in 1959 for assistance. In 1960, the year in which work on the dam began, UNESCO made an appeal for assistance to all its member countries. In it, UNESCO's Director-General Vittorino Veronese described the monuments in a new way, as a "common heritage" that belonged not to individual countries but to the whole world, saying that "treasures of universal value are entitled to universal protection" (Veronese 1960: 7). The waters of the Nile were going to rise, but the pharaoh and his temples had to be rescued.

UNESCO organised a major international rescue campaign in which engineers, architects, archaeologists, and others cooperated over many years. Modernisation threatened the monuments; but at the same time, modern methods were applied to avert the threats and salvage the temples. The alternative to allowing the pharaoh to suffer drowning and destruction was to move the temples, just as more than 100,000 Nubians in the area were relocated.

The plan was to save the temples of Abu Simbel, even though a few argued that the temples were not sufficiently outstanding as art, and that to do so was to help to preserve the image of a megalomaniac despot (e.g. Allais 2013: 32f).

There were thorough investigations and discussions of various technical, organisational, and economic solutions. In particular, there was a protracted dispute about the technical possibilities of salvaging the temples, with several competing proposals, while the waters of the Nile were rising in a menacing manner: a French proposal to protect the temples behind their own dam; an Italian one to raise them in one piece by means of hydraulics; a British one to make them visible under the water; another French one to tow them on a raft behind a dam; and a Swedish one to cut the temples into pieces and subsequently rebuild them at a new site. The Swedish proposal made by VBB (Vattenbyggnadsbyrån; now part of Sweco), which competitors rhetorically called a "butchering", was selected, and carried out behind a temporary protective dam. In 1965, the first stone block could be lifted from Abu Simbel's ceiling, soon to be followed by the face of Ramses II.

The temples of Abu Simbel were sawn up into stone blocks that could weigh up to 30 tonnes. The blocks were lifted to a temporary 
storage site, whereupon they were moved and used in a reconstruction 65 metres higher up and 200 metres further inland. The great temple was divided up into 807 stone blocks and the small one into 235. The temples with their colossal statues were reconstructed under two artificial hills, both of which were supported by arched domes made of concrete. Next, the relocated temples were given lighting and ventilation.

The move of Abu Simbel was the most spectacular operation, but other temples were moved as well. So-called "cultural oases" were formed around the temples moved from Kalabsha, Wadi esSebua, and Amada. Some temples were transferred abroad - Debod to Madrid, Taffa to Leiden, Dendur to New York, and Ellesiya to Turin. Individual monuments, and also sculptures and reliefs, were transferred either to the Nubia Museum in Aswan or to the National Museum of Sudan in Khartoum. Frescoes from the cathedral in Faras went to Khartoum and Warsaw. The Nubian campaign culminated with the move of the temples on the island of Philae to the nearby island of Agilkia, where they could be reinaugurated in 1980. However, it was not possible to save those fortifications and churches in Nubia that had been built of sun-dried brick. At Philae, numerous clay buildings had already disappeared in the floods after the construction of the first Aswan dam.

While the Aswan High Dam was being built, extensive archaeological surveys and excavations were carried out on a selection of sites along a 500-kilometre stretch of the Nile valley which was threatened with flooding. The area was divided up into concessions that were allocated to different countries and institutions. There were agreements to the effect that museums in the assisting countries would be allowed to retain half of the finds as a reward, a model that came in for subsequent criticism. In all, 27 countries were directly involved in the investigations in the Nubia campaign and 49 countries contributed funding; they included the United Kingdom (UK) and France, which had been at war with Egypt only a few years before (Säve-Söderbergh 1987: 223ff, 232f; Hassan 2007: 80, 90ff; 2009).

The flagship of the campaign was Abu Simbel, which was and is an icon of pharaonic Egypt and a well-known tourist destination; and the campaign led to an increased flow of tourists. The temples have featured in numerous contexts since their rediscovery, for example in travel literature, novels, films, and computer games. A line runs from Napoleon's Egyptian campaign to the tourism of today. Individual trips along the Nile made by well-to-do members 
of society paved the way for the charter tourism of more recent times. The bestseller A Thousand Miles up the Nile by the author and Egyptologist Amelia B. Edwards, which depicts a long stay at Abu Simbel, was thus an inspiration for new visits (Edwards 1877: 414ff; cf. Fagan 1975: 309ff). A famous work of fiction is Agatha Christie's crime novel Death on the Nile, in which Abu Simbel provides exotic scenery for an attempted murder (Christie 1937). The book is said to have been written at the Old Cataract Hotel in Aswan with a view over the river, and it has been filmed several times (e.g. by Guillermin in 1978).

After many tribulations, the temples could be opened again in 1968, first for notabilities and then also for tourists, more than ever before; for the attention given to the salvage campaign had generated greater awareness of the site. The temples of Abu Simbel with the face of Pharaoh Ramses II had become world famous. Visitors now came by bus from Aswan, by cruise ship on Lake Nasser, or by way of the nearby airport in order to spend a couple of hours at the temples.

However, since the Arab Spring reached Egypt in 2011, the number of tourists has fallen drastically; the disturbances have frightened most tourists off. But it could have been worse. Because with another kind of political development in Egypt - or if Abu Simbel had been located somewhere else in the Middle East - the temples might have been deliberately blown up or bombed more or less fortuitously, as has happened to monuments in Afghanistan, Mali, Syria, Iraq, and Yemen.

The international campaign organised by UNESCO attracted a great deal of attention at the time, and this interest has continued. The campaign has thus resulted in a number of technical reports, scientific publications, popular presentations, illustrated books, guidebooks, essays, newspaper articles, and films - about the investigations, the monuments, and their rescuing (e.g. Hansen 1961; Keating 1962, 1975; MacQuitty 1965; Franck 1967 film; Desroches-Noblecourt \& Gerster 1968; The Salvage of the Abu Simbel Temples 1976; Berg 1978; Säve-Söderbergh 1987; 1996; Kamil 1993: 98ff; Heimlich \& Weidenbach 2005 film; Hassan 2007, 2009; Allais 2013; Berg 2019).

In the course of time, the campaign, and especially the salvage of the temples of Abu Simbel and the concrete structures, have been described by those involved in effusive terms such as "a complete and spectacular success" (whc.unesco.org/en/activities/172), "a miracle", "an unprecedented enterprise”, "a resounding success”, 
and "a triumph" (Desroches-Noblecourt \& Gerster 1968: 7, 9, 110), "a modern cathedral or a new Temple" (The Salvage of the Abu Simbel Temples 1976: 162), a "triumph of civil engineering", and a "triumph for the Egyptian Government and the Egyptian authorities involved, triumph for UNESCO and its officials and for the international community" (Säve-Söderbergh 1987: 122).

And irrespective of whether it is told in the form of a travel novel or a technical report, the story of the campaign is narrated on the lines of a classic fairy tale - the threat that arises, the many obstacles and dangers that must be overcome, and the final resolution when the threat is overcome. Modernity (and humanity) threaten the heritage; but modernity (and human actions) will also bring solutions.

At the same time, these stories are infused with melancholy about Nubia, which disappears, and about the Nubian people, who are obliged to leave. And the Nubians' way of life is idealised as a contrast to the modern way of life (e.g. Hansen 1961; Keating 1975: 37ff, 208ff; Säve-Söderbergh 1987: 56ff; 1996: 193ff). Decades later, Nubians are shown recalling life at Abu Simbel, at the temples, and in the lost rural communities, while a return is being planned to a new Nubia (Heimlich \& Weidenbach 2005 film). Consequently, the campaign has generated both technical innovations and existential reflections.

Abu Simbel and the campaign also play a prominent role in the story of the adoption in 1972 of the Convention Concerning the Protection of the World Cultural and Natural Heritage, or, in short, the World Heritage Convention (WHC 1972; cf. Lutyk 1987: 6ff; Säve-Söderbergh 1987: 220f; 1996: 217f; World Heritage Information Kit, 2008: 7f). Here, for the first time, traces of the past are recognised as a universal heritage and therefore a common responsibility across national borders. And in 1979, the monuments relocated in Nubia - from Abu Simbel in the south to Philae in the north - were inscribed in UNESCO's World Heritage List (WHL) on the strength of being a masterpiece, a testimony to a lost civilisation, and an open-air museum that represents the unfolding of a long sequence of Egyptian pharaonic history (The World's Heritage 2018: 56; WHL 88, 1979).

Once the Nubian campaign had ended, the Egyptologist Torgny Säve-Söderbergh was able to summarise and justify the actions taken officially on behalf of UNESCO. Säve-Söderbergh wrote that even those involved might occasionally ask whether it was morally defensible to collect funds for the campaign in a world where millions 
were starving, and where innumerable children were dying of hunger or did not have a hope of achieving a reasonable standard of living. But he took the view that no one would have hesitated. The ancient monuments were said to be important, especially for the historical and cultural identity of the developing countries. Their preservation was not only a moral duty, but also a matter of social and economic importance. After all, the excavations and the salvage campaigns created jobs in areas of unemployment. And once they had been saved, the monuments became tourist attractions, which provided economic benefits. Finally, the antiquities and monuments that were transferred to foreign museums were described as "new ambassadors extraordinary" of Egypt and the Sudan (Säve-Söderbergh 1987: 137ff; 1996: 114f).

But in a critical reckoning with UNESCO and its World Heritage system, the archaeologist Lynn Meskell has recently designated the prioritisation of the monuments at Abu Simbel ahead of the local population and the campaign's archaeological investigations as "another hallmark of the modern conservation industry" and the salvage of the temples as a "theatrical spectacle" (Meskell 2018: 30, 32).

The pharaoh had been reflected in the Nile for millennia before the life-giving waters of the river became a menace. Stone block by stone block, the pharaoh and his temple at Abu Simbel were moved to higher terrain, salvaged from drowning, along with other temples. The pharaoh was salvaged in an international campaign that was both praised and criticised. In a quite fundamental way, however, the campaign arouses amazement.

\section{The paradoxes of Abu Simbel}

The campaign at Abu Simbel is a source of amazement because the site and the sequence of events seem to be full of paradoxes, in this context meaning absurdity or contradictions. The paradoxes, which can be formulated as questions or statements to investigate, are like Chinese boxes, one box sitting inside the next one:

\section{The impossible preservation of the past}

The past is being preserved for the future; but is preservation for the future at all possible? Abu Simbel had long since been eroded by sandstorms, one of Ramses' faces had been destroyed by an earthquake already during his reign, and the external painting of the 
temples is gone. The temples are to be preserved for the future; but in the long run, no preservation campaign or relocation, no elevation to heritage or even World Heritage, and no consensus can prevent change, degradation, and impermanence. Even the unique and irreplaceable masterpiece will be lost.

\section{The protection, preservation, and alteration of the past}

The past is to be protected and preserved; but do these endeavours mean that the past is altered? At Abu Simbel there was a conflict not only about whether the cliff temples could be salvaged at all, but also about whether this should be done. Should the temples be preserved at their original location or might they be moved out of their context? The cliff temples of Abu Simbel were salvaged from the rising waters of the Nile; but for that to happen they had to be sawn into pieces, lifted away, and reconstructed at a new location under an arched dome made of concrete. The temples were indeed saved, but they did not remain wholly the same as before their preservation, just as their surroundings changed radically. The shape of the hills was different from that of the original cliffs, and a new built-up area emerged with a port, hotels, housing, roads, and an airport. All the attention and the elevation to a World Heritage site, with more tourist visits, can also increase the wear and tear on the temples. Preservation means change.

\section{The protection and preservation of the past as an exception}

When the past is protected and preserved in one place, does that mean that the corresponding proportion of the past disappears from other places? The spectacular temples of Abu Simbel were salvaged, but at the same time other Nubian ancient monuments, settlements, graves, churches, and fortifications had to drown in the Nile after being investigated and documented; skeletons and pottery were often left in place. An even greater number of sites and objects could never be investigated. And salvage might mean transfer to museums abroad. So for every site that is preserved, there may be several that vanish. An apparent upturn in protection and preservation may thus conceal an even greater upturn in devastation. Protection and preservation are an exception. 


\section{The past and threats}

Threats may elicit history, memory, and heritage; but conversely, history, memory, and heritage may also create threats - and can the threats then themselves be transformed into history, memory, and heritage? The more Abu Simbel was threatened by drowning, the more the temples were held up as being worth telling about, remembering, and preserving. The threat was thus crucial in establishing the temples as heritage and, later, as World Heritage. Conversely, the cliff temples could have prevented the establishment of the Aswan High Dam and therefore the modernisation of Egypt. The preserved temples may also hamper a development that is not directly linked to income from tourism. In the future, then, the original threat, the dam - and perhaps also Abu Simbel's concrete arched domes - will be worthy of preservation as unique and irreplaceable testimony to the engineering skills of the 1960s. Clearly, history, memory, and heritage are interwoven with threats.

\section{The past and modernity}

Can history, memory, and heritage be a contrast to modernity while being part of modernity? The past has associations with the unchangeable, with stasis, with what has been, whereas modernity carries connotations of change, speed, and the future. Heritage was threatened by modernity; the temples of Abu Simbel were threatened by the Aswan High Dam. But heritage and World Heritage are modern phenomena. And modernity does not solely represent a threat; it can also represent a solution. The temples were salvaged by engineers and archaeologists using the most modern technology of their time, technology that may itself become history, memory, and heritage in the future. The past and modernity are also paradoxically interconnected.

\section{Modernity increases or decreases}

Can both an increase and a decrease in modernity give rise to history, memory, and heritage? That is, the more modernity, the more history, memory, and heritage; but also, the less modernity, the more history, memory, and heritage? The development of modernity leaves relics. At the same time, the decline of modernity breeds a renewed interest in the past, with more studies and an increase in preservation as well as investment in the experience economy. 
Paradoxically, there thus appear to be two opposing explanations of the relationship between the past and modernity.

\section{The crossing of boundaries}

Ultimately, does the establishment of World Heritage sites run counter to current trends? The World Heritage area that extends from Abu Simbel to Philae is a local example of a constantly increasing category of international protection and preservation adhering to uniform principles. World Heritage represents structure, unity, a unified whole, and universalism, even though the temples of Abu Simbel were fragmented so that they could be reassembled at a new site, deconstructed so that they could be reconstructed. World Heritage thus goes against a postmodern view of the present, which is supposed to be characterised by decay, multiplicity, fragmentation, the regional, and the local. World Heritage crosses boundaries.

However, the temples of Abu Simbel are only one of innumerable heritage sites that arouse a dormant sense of wonderment. Abu Simbel is only one of innumerable places that are supposed to be threatened and need to be salvaged, places where preservation and change are in confrontation, heritage and modernity standing face to face. And Abu Simbel is only one of many World Heritage sites; that is, a place that is held to be irreplaceable for future generations.

\section{The past is everywhere}

Viewed from a satellite or on a map, the World Heritage sites appear as points and lines spread across the continents of the globe. Every year sees an increase in the number of sites included in UNESCO's World Heritage List. While the list consisted of 12 World Heritage sites in 7 countries on its inception in 1978, there are now 1121 World Heritage sites in 167 countries (WHL, July 2019; Appendix 1). But the World Heritage sites are merely the peak of a gigantic iceberg. They only represent a tiny fraction of everything considered to be worth protecting and preserving as heritage.

The past is everywhere, and the past is expansive. This is because more and more is being viewed as history that ought to be told, memory that ought to be retained, or heritage that ought to be defended and preserved. Nothing tangible or intangible, large or small, visible or hidden, old or new, near or far is neglected. Preserve not just the temples of Abu Simbel (WHL 88, 1979), but 
also old trees, thatched roofs, International Style housing, factories, transformer substations, bridges, windmills, station communities, battlefields, silos, bunkers, minigolf courses, neon advertising, and car mortuaries. Preserve the royal ship Vasa and preserve the wreck of the Titanic! Preserve traditions, myths and legends, books, letters, newspapers, posters, graffiti, paintings, photographs, films, sounds, Internet websites, and digital metadata! Preserve the Earth! And preserve the light from stars at night! They are all threatened by change, by lack of interest or by other priorities, by silence and amnesia, by impermanence and destruction.

Where remains of the past have burned or been bombed, have decayed or simply disappeared, a radical restoration or reconstruction can recreate the past. Many monuments have thus risen again, and several are (or have been) included in the World Heritage list the Parthenon in Athens (WHL 404, 1987), Warsaw city centre (WHL 30bis, 1980, 2014), the Globe in London, the Stari Most bridge in Mostar (WHL 946rev, 2005), the Cathedral of Christ the Saviour in Moscow, the Church of Our Lady in Dresden (WHL 1156, 2004, delisted 2009), and mausoleums in Timbuktu (WHL 119rev, 1988). Others, such as the Berlin City Palace, are being processed; but UNESCO has given up on reconstructing the Buddha statues in Bamiyan in Afghanistan (WHL 208rev, 2003).

The current interest in the past is also seen in the constant increase in the number of museums, visitor centres, and recreated environments ranging across all periods, in places where the past is communicated and brought to life - from the copy of the Palaeolithic cave in Lascaux, France (WHL 85, 1979) via the JORVIK Viking Centre in York, England, the annual Medieval Week in Visby in Sweden (WHL 731, 1995), and the bringing to life of eighteenth-century Colonial Williamsburg in the US, to the Old Town in Aarhus in Denmark, which has a reconstructed urban neighbourhood from 1974. Here the tourist can either be an observer from a reassuring distance or participate actively in bringing another period to life. Historical role-playing games are another possibility.

A broad spectrum of literature, film, and television deals with historical themes, with a fluid dividing line between fact and fiction. This includes everything from Walter Scott's Ivanhoe and Umberto Eco's The Name of the Rose to Dan Brown's The Da Vinci Code, everything from Andrei Rublev to Gladiator and Downton Abbey. Indeed, the range of historical entertainment is enormous.

Then there is archaeology, my own discipline, which is only one of several methods of studying the past. Supported by both broad 
popular interest and relatively strong legislation, archaeological investigations (in Scandinavia at least) are more numerous, extensive, and ambitious than ever before. And gradually, archaeology has expanded to the point where it now covers all periods from the first humans to the present, even attempting to look far into the future.

We can investigate, preserve, and say more about the past than ever before. The methodological and technical developments have been nothing less than stupendous: aerial photography, metal detectors and georadar, pollen analyses, radiocarbon dating, dendrochronology, ice bore cores from inland ice, the use of geographic information system (GIS) mapping and drones, DNA analyses, and 3D scanning. And while we can look at the night sky with the naked eye and glimpse the Andromeda galaxy around 2.5 million light years away, we can use the Hubble telescope in an orbit around the Earth to see so far out into space, and therefore so far back in time, that we approach the birth of the expanding universe about 13.8 billion years ago.

The past is expanding, too. Almost regardless of what perspective we choose, the trend appears to be an increase, sometimes an exponential one. More history, more memory, more heritage, more World Heritage sites, more reconstructions, more museums, visitor centres, and role-playing games, more historical books and films. More archaeology, both further back in time and further ahead in time. In the wake of the upturn for heritage, there is growing heritage tourism; that is, tourism focused on traces of the past. In initiatives geared to increasing local or regional growth, the past is used as an attraction. The past is employed in order to create, strengthen, weaken, maintain, change, or discuss identities. Finally, heritage is increasing as a separate field of research and teaching.

When it comes to World Heritage, there is, in principle, global consensus. The basis for this claim is that since 1972, no less than 193 states have ratified the UNESCO Convention, while the United Nations (UN) has precisely 193 member states (whc.unesco.org/en/ statesparties; www.un.org/en/member-states/index.html; September 2020; Appendix 2). Across all variations with regard to history, culture, language, religion, politics, and economics, states are hence able to agree about the meaningfulness of a universal natural and cultural heritage.

But why? Why this fascination with the past? Why so much history, memory, and heritage? Why try to retell, remember, preserve, reconstruct, bring to life, popularise, dig up, and use the 
past? What is the point of all this past in our present? And why the consensus?

Is the expansion an expression of a desire to attain greater knowledge about the past and therefore about ourselves, a desire accompanied by willingness to allocate more resources to such efforts? Is the expansion a symptom of a chronic nostalgia in a society in crisis, which creates an increasing need? Or is the expansion an expression of a growing moral duty to tell about, remember, or preserve remains of previous generations? Is it thus to be interpreted as an expression of progress or as a sign of decay? Are we witnessing people's increasing ability to tell about, remember, and preserve - or have people lost the ability to be silent, forget, and lose? Why not permit silence, oblivion, and impermanence? Why not simply let the past remain the past?

There is more than ever to tell about, remember, and preserve; and the desire to do these things also seems to be greater than ever, at the same time as the ability to do so is improving every day. But this endeavour can only be a postponement of the inevitable. For in the long run, no narrative, no memorial of stone or bronze, and no designation as heritage or World Heritage, no archive, library, or museum, no screen of bulletproof glass or global consensus, can resist change and therefore impermanence. This struggle is doomed to fail and therefore appears pointless. The preservation of the past is impossible, and yet efforts are constantly being made to attain this goal.

This brings to mind the myth of Sisyphus, King of Corinth, who pushes a great stone up a mountain; but then on reaching the top, the stone rolls down to the plain again. Sisyphus is the absurd hero, who toils in vain forever in the land of the dead as punishment for having once put Death in chains, that is precisely for trying to prevent impermanence. Happy or not, Sisyphus toils in sweat and dust, as he is compelled to do by Zeus the god (Camus 1942 (French): 163ff; 2005 (English): 107ff). But why then do we human beings toil with the past, if it is all in vain? Are we toiling with a stone block that is getting bigger every year? Do we have the freedom to let the stone lie, or are we forced to continue? Do we have a choice?

\section{Multiple meanings}

At first glance, protecting and preserving the past for the future may seem to be both absurd and paradoxical in that those two pursuits 
may be thought to be unreasonable and full of contradictions; but they are not meaningless in the sense of being without meaning. On the contrary, there is a plethora of ideas about why and how the past is actually protected and preserved - and how it can, should, or has to be protected and preserved. Indeed, the sheer quantity of perspectives, concepts, justifications, values, interpretations, explanations, and positions is overwhelming.

Numerous terms appear in the debate about the meaning of the past. They refer to perspectives, disciplines, institutions, objects, and processes: history, historicise, historicism, historicity, historical consciousness and use of history, archaeology, antiquity, artefact and ancient monument, memory, site of memory and politics of memory, monument, monumentalise and memorial, museum, musealisation and museology, heritage, heritagisation, use of heritage, politics of heritage, and heritage process.

Just as the terms are numerous, many reasons are quoted for studying, retelling, remembering, protecting, preserving, or using remains of the past. These reasons may be in the nature of arguments for a particular perspective, for the existence of an academic discipline, or for the activities of an institution: Why the disciplines of history and archaeology? Why erect monuments and memorials? Why establish archives and museums? Why categories such as heritage and World Heritage? As a source of knowledge! To be able to tell! As a moral obligation! The reasons may also be in the nature of values that are emphasised. And the choice may be between telling and staying silent, between remembering and forgetting, and between preservation and destruction.

Reasons for occupying oneself with the past are often formulated in specific situations that require a justification. A lengthy argument may then be reduced to rhetorical slogans, such as "The past for the future" and "Heritage is a resource". Differences regarding interest in the past may also be subjected to critical analyses and accounted for in the light of ideological and economic trends in society. And the importance of the past can be understood against the background of more fundamental circumstances - either humans as creatures characterised by their historical self-consciousness or society as a phenomenon dependent on its history for its ability to function. In reasons, explanations, and understanding, we recognise the three timescales of the French Annales school - the event, the conjuncture, and the long-term structure.

The field can display sharp contrasts between the rhetorical slogans for or against protection and preservation - via the critical 
analyses of how the past has been or may, should, or will be used to categorical statements to the effect that history, memory, and heritage are expressions of a society that is either rising or decaying.

The Past is a Foreign Country (1985), by the historian and geographer David Lowenthal, became a classic soon after its publication a classic that has frequently been referred to and quoted. The Past is a Foreign Country thus belongs to the academic canon, has been called the "Bible" of heritage, and was crucial to the establishment of heritage studies as a separate field of research from the 1980s onwards. Three decades later, Lowenthal returned with a revised and expanded edition: The Past is a Foreign Country - Revisited (Lowenthal 2015).

The Past is a Foreign Country begins by stating that "The past is everywhere" (Lowenthal 1985: xv; 2015: 1). Lowenthal then goes on to present, with example after example, quotation after quotation, the overwhelmingly numerous and various ways in which the West, in particular, has viewed, related to, and used the past. The book hence gives the impression of being a great collage, more of a collection of examples than an analysis - a collage in which everyone can find a perspective to be inspired by, or a concrete fragment to reuse.

The many examples and quotations blur the dividing line between what others have written or said - and think - and whatever view Lowenthal himself may hold. And Lowenthal explicitly says that he does not want to write a manifesto; that should be the preserve of prelates and politicians (Lowenthal 2015: 2). But The Past is a Foreign Country is in fact a long manifesto, held together by a nostalgic recurring theme. Because at the same time as Lowenthal reproaches others for making judgements about the past, he makes judgements himself, time and again, about how the past has been and is being put to use. Irrespective of his choice of perspective, or of examples of how the past has been used or how the present relates to the past, Lowenthal is consistently dissatisfied and critical. There is too much of the past, and it is all wrong.

Here is a selection of examples and quotations to illustrate Lowenthal's critical attitude. About anachronisms and modernisations of the past, he writes that these "ahistorical perversions are widely accepted by the general public"; the general public "knows less and less"; archaeological data are "elusive and slippery", and preservation is "cramping creativity"; popularity leads to decay, wear and tear, destruction, restrictions, and screening; tourism is followed by the vulgarity of "constant cockneyfication"; and the 
present is characterised by "historical illiteracy", while wretched history "is no longer the privileged mode of access to the past [that] it used to be" (Lowenthal 2015: 21, 394, 422ff, 590, 596). Nostalgia is characterised by such words as "epidemic", "modern malaise", and "drug" (Lowenthal 1985: 4ff; 2015: 31ff). And with the aid of a quotation from the architect Rem Koolhaas, Lowenthal compares heritage with a "metastasizing cancer" (Lowenthal 2015: 588).

Lowenthal's sweeping criticism of heritage is evident in his subsequent book, The Heritage Crusade and the Spoils of History (1997), which opens by stating that heritage is everywhere. Now the torrents of invective rain down on the reader. Heritage is not only good, but also "oppressive, defeatist, decadent". Heritage is "hyped", "nostalgic", "its growth [is] also alarming", it "causes chaos", and it is "rubbish" and "a sacred cow" (Lowenthal 1997: ix, 5ff, 10ff). Lowenthal writes that "[w]orship of a bloated heritage invites passive reliance on received authority, imperils rational inquiry, replaces past realities with feel-good history and saps creative innovation" (Lowenthal 1997: 12). Heritage is "corrupted by being popularized, commoditized, and politicized" (Lowenthal 1997: 87, also 88ff). History and heritage are described as mutually contradictory. "History seeks to convince by truth and succumbs to falsehood. Heritage exaggerates and omits, candidly invents and frankly forgets, and thrives on ignorance and error" (Lowenthal 1997: 121). "Heritage is immune to critical reappraisal because it is not erudition but catechism; what counts is not checkable fact but credulous allegiance" (Lowenthal 1997: 121). "To vilify heritage as biased is thus futile: bias is the main point of heritage. Prejudiced pride in the past is not a sorry consequence of heritage; it is its essential purpose" (Lowenthal 1997: 122).

After having read both the original and the later edition of The Past is a Foreign Country as well as The Heritage Crusade and the Spoils of History, and having listened to several lectures given by Lowenthal, I wonder whether the canonical status of the books is, in fact, due to the criticism, or has come about in spite of the criticism, or has perhaps evolved because many people have failed to go beyond the books' titles and lists of contents.

Lowenthal views not only the past but also his own period as if he were a tourist on a visit to a "foreign country". He takes a distanced view of the present's use of the past as something strange, without wanting to understand, without useful explanations, and without constructive proposals for improvements. There are only small and scattered attempts to understand or explain why the past 
is protected, preserved, used, discovered, and created, and why it changes. And yet, more than anything else, all his examples and quotations actually do show, with overwhelming empirical support, that people's relationship to the past is something essential. Without understanding or explanations, preservation becomes something absurd, something done for its own sake: "preservation has become a prime end in itself" (Lowenthal 2015: 592).

Interspersed with the criticism are small attempts at explanations. On the one hand, Lowenthal takes the view that modernisation has created anxiety and nostalgia, that the increasing tendency to tell, remember, and preserve is due to growing speed and volatility (Lowenthal 1985: 399; 2015: 417, 596). The more change, then, the greater the need for the past. On the other hand, angst and nostalgia are also said to be due to doubts about progress and modernity (Lowenthal 1985: 11ff; also 1997: 1, 10f; 2015: 36ff, 417). Consequently, Lowenthal considers that angst and nostalgia are caused by both modernism and postmodernism.

Modernism without faith is exactly what characterises postmodernism, according to the journalist and art historian Robert Hewison, who has also written critically about heritage: "Postmodernism is modernism with the optimism taken out" (Hewison 1987: 132).

The debate about the past, history, memory, and heritage thus reveals deep disagreement about most matters: the concepts that are relevant, the motives or values that are important, the interpretations or explanations that are valid, and also the attitudes that should prevail. There is also a debate about whether a newer age should be given priority ahead of an older one - for instance, whether the modern industrial heritage is more important than the Viking Age's rune-stones or the Stone Age's kitchen middens; about whether preservation is a relatively new or old phenomenon; about whether the remains of the past should be protected and preserved, can be used or even consumed; about whether or not authenticity is crucial for heritage; and about whether heritage is a reality or a construction in the present. It is thus easy to become somewhat confused when confronted by the multiplicity of concepts, justifications, values, and - not least - would-be authoritative analyses and attitudes that appear to conflict with one another.

It is tempting to regard this multiplicity as an expression of the postmodern condition. This is a concept formulated by the philosopher Jean-François Lyotard. The condition is supposed to be characterised by the dissolution of the great narratives. Religions, 
ideologies, and science lose their credibility. Faith in progress and the modern project has expired. What is left is the singular, subjective and individual, the multicultural and eclectic (Lyotard 1979 (French); 1984 (English)).

In the face of the postmodern condition, my investigation might come to an end. There is no reason to search any further; satisfactory answers already exist. The answers are multiple, complicated, and entangled in one another. And no answer is better than any other. So why look for more concepts, justifications, values, or theories? The world with its history, archaeology, memory, monuments, memorials, archives, museums, heritage, and World Heritage is too open and complex to be comprehensible.

Multiplicity is undoubtedly a fact; but it is debatable whether our present age is actually in a postmodern condition. First, our time is not strikingly postmodern; rather, it is hypermodern. Second, if our age is or has recently become postmodern, previous ages have certainly presented the same symptoms of multiplicity and confusion. And, third, different parts of the world may be dissimilar, so it is not possible to generalise about a prevailing global condition.

The present is not unequivocally postmodern. Consequently, the great narratives have by no means expired. It is possible that many people question faith in progress and modernity, particularly in the West, in other words in Europe and North America; but this faith is still gaining ground in other parts of the world, especially in Asia. The great global contexts are more important than ever; the economy and the climate are bringing people together around new common narratives; and religion is once more on the political agenda every day of the week. The postmodern condition is hence not dominant from a global perspective.

The concept of the postmodern condition assumes that the modern period was somehow different, an organic "golden age" of great narratives, characterised by the universal, objective, and collective, the monocultural and coherent. Here, though, the postmodern philosophers may have been seduced by the narrative of progress that they themselves criticise; or they are captives of their own rhetoric, which marks a distinction between the modern and the postmodern. For the narrative of progress gives history a direction, a direction where whatever deviates from its main line is not told, remembered, or preserved. Both the modern period and the early modern and pre-modern period possessed a multifarious abundance of small and great narratives. A canonisation of one line of development around progress closes off the alternative 
narratives, memories, and possibilities. All ages have been "postmodern" if the simultaneous existence of many small narratives is a crucial criterion: we have always been postmodern.

The present has always been characterised by a multiplicity of opinions, confusion, and uncertainty about the future. It is only when a distance has opened up to a period or epoch that a rounded narrative is put in place through a process of canonisation, in which something is selected as valuable ahead of something else. Something is told, remembered, and preserved while something else remains unsaid, is forgotten, and disappears. At a distance, the past can be surveyed, simplified, and fitted into a greater canonical narrative, with a given direction, about what was typical of the period. But a deeper and broader examination of earlier periods uncovers a swarm of alternative views, metaphysics, religion, superstition, speculations, and errors that are not given a place in the textbook narratives about the progress of reason and science. It is the canonised hero of reason to whom memorials are devoted, and whose intellectual legacy is protected and preserved for posterity.

A first example that may be mentioned is the view taken of the past, artefacts, and ancient monuments in Denmark and Sweden in the seventeenth century, with names such as Ole Worm and Johannes Bureus. A close study of contemporaneous sources reveals that these views about the past were intimately related to religion and magic and were much more varied and full of contradictions than previously assumed (Svestad 1995: 75ff; Jensen 2002).

A second example is the mathematician and physicist Isaac Newton, who is often presented as a pioneer of modern science but was influenced by religious motives. Newton is famous for his revolutionary theories of universal gravitation, motion, light, and colour. But at the same time, he sought to combine what should, in a modern view, be kept separate, namely the magic and the exact, the occult and the rational. Throughout his life, he studied alchemy and theology alongside mathematics and physics. Newton thus employed several methods which he regarded as equivalent in his endeavour to reach the truth and the divine (Dobbs 1991).

As a third example, the physicist Hans Christian Ørsted combined religious ideas and Romantic natural philosophy with physical experiments. When Ørsted discovered electromagnetism, he was thus inspired by Romantic ideas about the unity of natural forces. In his view, he had made an experimental demonstration of the spirit of nature, which reflected the thoughts of God (Lindborg 1998). 
Multiplicity and confusion around history, memory, and heritage may also be due to the actual volume and variation of the relevant phenomenon. The past is expressed in everything from doctoral theses to novels and role-playing games, from national archives to private photo albums, and from the Abu Simbel of antiquity (WHL 88,1979 ) to the modern Sydney Opera House (WHL 166rev, 2007). The field is so large, and the questions are formulated so broadly, that the path lies open to many different and mutually contradictory replies.

In addition, there is marked multiplicity in the division into disciplines and institutions, each with their own discourse or "conversation"; that is, each with its own professional language, circulation of ideas, questions, perspectives, methods, sources, practice, justifications, motives, and values. The past is illuminated by numerous subjects, each of which can be further divided into a number of subspecialities. In the same way, there are innumerable institutions such as archives, museums, libraries, visitor centres, research centres, and administrations displaying far-reaching internal specialisation. Multiplicity may also be based on quantitative growth. There are quite simply more trained historians, psychologists, archaeologists, heritage researchers, and other specialists than ever before, and therefore also more conflicting opinions (Kristiansen 1996; Evans 1997: 171ff).

This multiplicity is a double-edged phenomenon. On the one hand, it entails an enriching pluralism, in which reality is illuminated from several vantage points. On the other hand, it easily leads to confusion and despondency. Understanding and explanation, the possibility of criticism and change disappear when numerous variations and details are allowed to dominate. Similarities and wider correlations go undetected. A unified view becomes an unachievable utopia.

However, two distinct attitudes to the traces of the past - two diametrically different cultures - run right through all this multiplicity and confusion.

\section{Two cultures}

Two cultures are separated by a gap. One is science and the other is literature (or the humanities). They do not know each other and they cannot enter into a conversation. That was the claim made by the physicist and author C. P. Snow in a lecture in Cambridge in 1959 (Snow 1959). This gap originated from a division of the scientific disciplines of the nineteenth century into analytical 
and explanatory natural sciences on the one side and interpretative and understanding humanities on the other. And explanation and understanding are still two complementary ways of approaching knowledge (cf. Wright 1971), so there is no concept that could unite explaining and understanding, unite causes and intentions.

Snow's idea about the two cultures had a great impact in an era in which the Cold War created a polarisation between West and East. At the same time, it is easy to see that the idea of the two cultures also sprang from Snow's personal experience as both a physicist and an author. But even if Snow's powerful pair of concepts has long been outdated, I would submit that there is a current gap between the two cultures with respect to their view of history, memory, and heritage. Despite the comprehensive affiliation to the World Heritage Convention, there is still no consensus about heritage or World Heritage.

The two cultures of heritage originate from different roles and therefore dissimilar perspectives - on the one hand antiquarian "management" and on the other hand critical studies in the academy. But the cultures share a focus on threats, in the first to heritage and in the second from heritage. In addition, the division between the two cultures often, albeit not always, coincides with the division between essentialism on the one hand and constructivism on the other. The managers thus see the past and the heritage as really existing, whereas the critics view the past and heritage as constructions for negotiation. I refer to the first culture as Canonical Heritage; the other calls itself Heritage Studies or Critical Heritage.

The first, and canonical, culture of heritage is characteristic of the heritage managers. Resting on laws and conventions, it is supported by popular engagement. It is found at international institutions such as UNESCO, national institutions such as English Heritage/Historic England, the Swedish National Heritage Board, the Directorate for Cultural Heritage in Norway, and the Danish Agency for Culture and Palaces, and at archives, libraries, museums, foundations, and associations. A characteristic of the first culture is that heritage is regarded as being under threat, and that it ought to be defended and preserved for the future. Representatives of this culture describe developments as a constant struggle against time and impermanence for better documentation, protection, preservation, and use. A boom or an upturn for history, memory, and heritage is seen as a sign of health and as progress. Heritage is already, or should be, central as a destination in a growing experience economy. And heritage is associated with words such as inheritance, memory, resource, knowledge, 
values, democracy, multiplicity, and sustainable development, all meant in a favourable sense.

We encounter the first culture in general works about institutions, specialist disciplines, and heritage, in which it is possible to follow developments from the very first examples of history writing, archaeological excavations, or protection up to research, management, and communication in our own age. The past, with its texts, images, objects, monuments, and landscapes, has been threatened through the ages by silence, oblivion, and destruction; but it can and should be salvaged for posterity. A consistent theme running through these narratives is threats to the heritage, and attempts to avert them. The salvage of the temples of Abu Simbel is a prime example in the first culture's own history of successful campaigns for protection and preservation. History, monuments, and heritage are presented as being worth protecting, preserving, being aware of, and visiting. In particular, all the World Heritage sites are proudly presented on signs, on websites, in adverts, in brochures, in magazines, and in abundantly illustrated works (e.g. whc.unesco.org; Lutyk 1987; Anker \& Snitt 1997; Grundsten \& Hanneberg 2000; Hanneberg 2012; The World's Heritage 2018; worldheritageswe den.se).

Heritage's second, critical, culture is found especially among a number of academics active at universities or research centres, or as independent scholars. It is present at universities, where networks are established around courses, journals, series of books, conferences, and centres with the word "critical" as their pivotal point, for example in the network called the "Association of Critical Heritage Studies" (criticalheritagestudies.org). The criticism appears across a broad scale - from criticism of the selection of heritage via criticism of how heritage is preserved and used to rejection of heritage as an idea.

One characteristic of the most radical criticism of heritage is the notion that the past is a burden and a menace to society. The unfavourable consequences of too much history, memory, or heritage are emphasised. Mass tourism to heritage destinations is a problem. An upturn for the past is thus seen as a symptom of disease and crisis. The upturn is described not as a boom, but as a mania. And history, memory, and heritage are associated with words such as myth, flight, therapy, trauma, spectacle, obsession, and inflation, madness and stress, taboo, totem and fetish, cult and crusade, industry and musealisation - all obviously intended in an unfavourable sense. 
Radical critics thus describe the past as a burden, a stone of Sisyphus, and a threat to society. Stored artefacts are described as "archaeological waste" and archive documents as "archival waste" (e.g. Beckman 1998: 36f). The widespread fixation with the past is diagnosed as neurotic and repressive, an expression of a sick consciousness and fear of death (Brown 1959: 87ff). Culturalism with its notions of identity is described as an epidemic virus (Hylland Eriksen 1996). Heritage inflation is diagnosed as a narcissistic syndrome leading to either neurosis or madness (Choay 1992 (French): 187ff; 2001 (English): 164ff).

The analogy with disease is already to be found in the work of the philologist and philosopher Friedrich Nietzsche. His "untimely meditation" Vom Nutzen und Nachteil der Historie für das Leben (On the Use and Abuse of History) was originally intended to appear under the title "The Historical Disease". Nietzsche described his age's preoccupation with the past as a "consumptive historical fever" that should be countered with poison, ointments, and medicines. Nietzsche took the view that history, which ought to serve and promote life, had become a burden and a drawback. With its ideals, the art and culture of antiquity was a "yoke of the past". The present was described by Nietzsche as saturated with history, and it was to be cured by a diet of oblivion and art. For the past was hostile and dangerous. It weakened personality, fostered self-righteousness, impeded maturity, promoted epigonism, and developed both cynicism and egoism via self-irony (Nietzsche 1874 (German): Vorwort, Chapter 8, 10; 2005 (English): Preface p. 3f, Chapter VIII 47ff, Chapter X 65ff).

Another widespread analogy is with religion - also meant in an unfavourable sense. The whole sphere of history, memory, and heritage can be seen as a civil religion with relics and rituals, a religion that creates cohesion around the nation and a national identity. Museums are compared with temples or churches, the objects exhibited with relics, museum staff with priests, monuments with religious buildings, tourists with pilgrims, and mass cultural tourism with a World Church (e.g. MacCannell 1976: 42ff; Horne 1984: 1ff; Choay 1992 (French): 101ff, 128f, 158ff, 186; 2001 (English): 87ff, 111f, 139ff, 163; Beckman 1993a: 31f; 1998: 32ff; Duncan 1995: 7ff; Hylland Eriksen 1996: 85).

This criticism, in all its forms, is found in Lowenthal's work. There is criticism to the effect that UNESCO defines heritage too narrowly according to a Western way of thinking, focusing on preservation of the material; that is, the intangible, which is of greater importance 
in other cultures, is neglected (Lowenthal 1997: 20). Besides, the past is said to be merely preserved instead of being used creatively (Lowenthal 1985: xvii, 384; 2015: 413). There is general criticism, full of invective, of the past and heritage (Lowenthal 1985: 4ff, 64; 1997: 5ff, 10ff, 87ff, 120f, 189; 2015: 31ff, 132). The analogies to both disease and religion are in evidence here. In The Past is a Foreign Country, nostalgia is described as an epidemic disease (Lowenthal 1985: 4ff; 2015: 31ff). And in The Heritage Crusade and the Spoils of History, heritage is compared with a new folk belief, a secular religion, and a crusade, just as heritage institutions are compared with the Church (Lowenthal 1997: 1f).

But analogies with disease and religion hardly contribute to greater understanding of the importance of the past in the present. The analogies only mean that questions are given new labels, that the problem field is reformulated in new spheres which are at least as complicated or enigmatic. Then, instead, the question becomes: Why diseased? Why neurotic? Why pilgrimage? Why crusade? The purpose of the analogies appears as a rhetorical strategy, in which the choice of words is geared to demonstrating how negative or meaningless heritage is. It is about invective, not about understanding or explanation.

If there is any doubt as to which of the two cultures of heritage one is encountering, the language can be revealing. While the first, canonical, culture talks about history, memory, and heritage with respect and reverence, as something elevated, the tone in the second culture may, as an antithesis, be surprisingly disrespectful, sarcastic, derisive, or directly contemptuous of both heritage and its managers. Although the defamatory tone can be traced back to the style of Nietzsche, Lowenthal's books also seem to have set a standard here that several people with the same attitudes have striven to emulate (e.g. Beckman 1993a; 1998).

However, a critical reckoning with both traditions of heritage is long overdue (cf. Winter 2013; Aronsson 2015: 168f). The traditions have developed into conformist, self-corroborating discourses without any mutual dialogue. A continued reckoning is needed with the managing canonical tradition, whose protection and preservation are uncritically regarded as part of the Enlightenment project and progress; so is a reckoning with the critical tradition when it gets stuck in non-constructive criticism and merely repeats itself by constantly providing new examples.

On the one side are those who evidently worship the past and the cultural heritage, and on the other side are those who are 
discontented with them both. But if we want to understand and explain the importance of the past in the present - that is, understand and explain the importance of history, memory, and heritage then the gap between these two cultures needs to be overcome. For an inquiry cannot focus solely on the arguments on one side - that is, either on all the good arguments for telling, remembering, and preserving, or on all the good arguments (or invective) to the contrary. My inquiry will try to bridge that gap and, if possible, fuse the canonical and the critical. In addition, greater conceptual, methodological, and empirical precision is required since, up to now, central concepts have been used in a somewhat haphazard fashion, various random examples being thrown into the debate one after another as ad-hoc arguments, and arguments often being replaced by rhetoric.

\section{Archimedean points}

The ancient mathematician Archimedes is supposed to have said, "Give me a place to stand, and I will move the earth." This wording has created the metaphor of the Archimedean Point as a name for an immoveable, secure, and certain fixed place. Now, however, the metaphor is generally used to assert that a fixed place of that kind no longer exists, insofar as it ever did. There is not supposed to be such a thing as a fixed place, a true, objective, or certain starting point. In the postmodern condition, an almost nihilistic relativism is unavoidable.

But the need for an Archimedean point becomes evident when one confronts the debate about the past. For there is great confusion here, produced by strange paradoxes, innumerable examples, multiple meanings, and conflicting explanations. So give me a fixed place where I can stand and therefore a viewpoint I can use, and then I can try to understand and explain why the past apparently turns up everywhere.

Over the years, I have considered, planned, initiated, and then rejected (at least) three different starting points for an investigation. The first was the well-known and unique, while universally valid, archaeological discovery where we stand face to face with the person of the past: the mummified body of the Tollund man at Silkeborg Museum in Denmark. I then looked at musealisation, with its shifting trends, from a long-term perspective: the founding of museums in Scandinavia as a population covering the whole spectrum from the great national museums to the Hasse \& Tage Museum in Tomelilla in Sweden, called the world's smallest film 
museum. And finally, the spectacular blasting of a heritage - and later World Heritage - site: the destruction of the Buddha statues in Bamiyan in Afghanistan in 2001 (WHL 208rev, 2003).

Where the field of the past is great and unbounded, I choose to focus on one out of several possible perspectives, namely on heritage, an area where David Lowenthal's books, The Past is a Foreign Country $(1985 ; 2015)$ and The Heritage Crusade and the Spoils of History (1997), possess canonical status. But further precision is needed.

Despite the influence of Lowenthal, studies of heritage are surprisingly often restricted to individual sites, a region, or a nation, in the same way as international perspectives are often restricted to previous colonies. Both heritage's canonical culture and heritage's critical culture generally keep to a national discussion, as if the term heritage had undergone its own independent development within the borders of a state (e.g. Anshelm 1993). This geographically restricted scope may be due to a practical dependence on the respective area of responsibility and field of interest of institutions. It may also be due to connections with questions of identity and politics, both of which are often restricted to the national stage. And the national or colonial scope may be due to linguistic limitations or convenience. But even if the nation is an important unit, it is neither natural nor unproblematic as a methodological boundary, and it needs to be explored in a global context (cf. Smith 1983; Wimmer \& Glick Schiller 2002). Without a broader perspective that crosses borders and shatters the national "iron cage", it is, in my opinion, not possible to understand or explain heritage as a phenomenon, let alone to account for the global expansion of heritage.

In studies of both the past and the present, we often resort to perspectives that are characterised by dichotomies. As academic trends shift, either one or another perspective is given renewed attention: the special or particular as against the general or universal, the local as against the global, and the national as against the international. But in order to understand and explain heritage, it is necessary to unite these perspectives. Heritage as a phenomenon is both local and global - heritage is "glocal". Developments at the local level are affected by global trends - and the global has to take a position in relation to the local (Robertson 1995). But where, then, is the starting point that can shed light on heritage from a glocal perspective?

Abu Simbel in Egypt has several of the characteristics that an Archimedean point of heritage is required to possess. Thus the cliff 
temples of Abu Simbel hold a central position in the debate about the protection, preservation, and use of heritage. Abu Simbel is a world-famous and popular destination, even though the Arab Spring and the subsequent conflicts have reduced the number of tourists. The temples were threatened by drowning and destruction on account of the erection of the Aswan High Dam, but after several years of discussions about principles and technical solutions, the temples were salvaged in an extensive international campaign under the leadership of UNESCO. And a few years later, Abu Simbel was elevated to World Heritage status along with other Nubian monuments. But instead of remaining at Abu Simbel, the temples can be used as a vehicle for engaging in an exchange between the local and the global, from Abu Simbel to all World Heritage Sites and back again. Therefore, instead of choosing one Archimedean point I choose many; that is, the apparent stability of a growing network of many sites.

From a glocal perspective, heritage may be represented by World Heritage, which has found its way not only to Abu Simbel, but also to numerous monuments, buildings, places, and landscapes around the globe. The category of World Heritage is a growing international canon that is well defined and particularly well documented. World Heritage permits both a total overview and a focus on selected examples. World Heritage represents both the past and the present. The World Heritage sites are accompanied by various expressions defining their values, their proper use, and reasons for their status. World Heritage sites may be linked to questions related to canonisation, memory, and oblivion, crises and compensation, modernity, museums, and traditions. And World Heritage sites are relevant to current questions about economic development, politics, identity, rights, and conflicts (cf. Labadi \& Long 2010). World Heritage sites, with Abu Simbel as an example, are also "good to think with" (LéviStrauss 1962 (French): 128 "bonnes à penser”; 1963 (English): 89).

World Heritage sites were chosen as the Archimedean points of the present investigation, partly because they can represent heritage both locally and globally and partly because they are readily accessible as empirical data, and therefore do not detract from the questions, perspectives, and debate. There is no need for timeconsuming archive or storage studies or for demanding excavations, conservation, documentation, or digitalisation to make the material accessible and usable.

While new methodological conditions were created for the writing of history with the art of printing in Europe from the fifteenth 
century, and for archaeology and history of art with the railway and mass production of images in the nineteenth century, aspects of modernity in the form of computer technology and the Internet are creating new conditions for heritage studies in the twenty-first century. Without exertion I am able, from my location in southern Sweden, to visit World Heritage sites all over the world with the aid of Google Earth, Google Street View, and UNESCO's websites. Modernity is hence both a condition for my inquiry and part of the modernity that is to be investigated and discussed.

The World Heritage sites are complex entities. On the one hand, World Heritage is a concept, a word with a well-defined meaning which refers to a carefully defined number of sites that can, in principle, increase without end. On the other hand, every single World Heritage is an individual, unique site with its own history and own set of physical circumstances. The World Heritage sites thus represent both an abstract idea and a concrete materiality, and they must therefore be investigated from several perspectives and using several different methods. Concepts can be confronted with the material both in order to inspire and in order to meet resistance.

But do the World Heritage sites create or reflect a world? Is World Heritage something that exists and can therefore be discovered? Or is it something that is constructed, and that creates a new reality? This is the same problem as in a discussion of whether facts are discovered or constructed in a laboratory (Latour \& Woolgar 1979; also Febvre 1949 (French): 239; 1973 (English): 36f), and whether a map reproduces or constructs the world (Wood 1993). Here the field of social sciences and humanities has been characterised by constructivism since the 1980s; that is, the view that we construct the world with the aid of words and images.

A World Heritage site can be discovered as a place, but it is constructed as a concept. And there is a compromise or a third standpoint between objectivism and constructivism, between discovering and constructing facts. It is not a question of knowledge either existing or being created, but of the world's being investigated with the aid of human-made instruments. But heritage and World Heritage are not only about technical instruments; they also involve the senses and language.

The world may be observed and changed from innumerable angles that complement and enrich one another. The picture of the world varies as perspectives shift. Just as colours show part of the world, and just as the Hubble telescope shows light from the cosmos in a limited section of the spectrum, a map shows 
the world from one of an innumerable number of possible perspectives. The map is a model of the world that connects theory with reality: it is an idealised representation of the world. And since the world is infinite and constantly changing, the map can never be more than a methodological approximation of the world (Giere 2006). So the telescope and the map are - just like the pen, the book, and the computer - tools that bridge the gap between objectivism and constructivism, between the world as it is and our view of the world. We do not experience the world as it is but as our instruments, senses, and experience permit us to perceive it (Eagleman 2016: 35).

Questions concerning the importance of history, memory, and heritage cannot be answered with a clear yes or no. Nor can they be answered with a mathematical formula or a number. There are no definitive answers. Instead, we are dealing with an interlocking of understanding and explanation where the choice of perspective is pivotal to the shaping of the answers.

\section{Arche, archaeology, and order}

The study of the past is split up among numerous subjects and institutions, each with its characteristic designation, its perspective, its methods, its source material, its period, or its preferred geographical area. And inside each subject or institution, there are discussions about objectives, boundaries, and identities, especially when the field is to be defined in relation to other fields. The universal, overarching, or common in relation to the past and the present is forced to give way to far-reaching antiquarian and academic Balkanisation. What is needed here is an amalgamation of that which has been divided, a fusion of canonical and critical perspectives.

Linguistically, the first part of archaeology as a word may have its origins in pre-Socratic philosophy. The first person to have used archai or arche as a concept is said to have been the philosopher Anaximander. Arche was derived from the verb archo, which meant "to begin" or "to reign". In philosophy, arche came to mean beginning, origin, first principle, ultimate cause, first material, or axiom. Arche was a "substrate" - an underlying layer. Arche was the origin of everything, boundless, eternal, immortal, and divine (OED: I, 608; Malina \& Vasícek 1990: 3ff; McKirahan 1998).

In philosophy, archaiologi'a or archaeology then came to mean the study of a distant past, or speculation about events with regard 
to which there was no proof. In its earliest meaning, archaeology is hence unbounded in relation to sources, periods, and geography. But when archaeology was disciplined into a field of inquiry and then became an academic subject in the nineteenth century, it was limited to the study of material culture with the aid of the methods of typology, stratigraphy, and analogy. And archaeology then came to be associated, first and foremost, with excavation (Malina \& Vasícek 1990: 3ff; Schnapp 1993 (French): 60ff, $275 \mathrm{ff} ; 1996$ (English): 60ff, $275 \mathrm{ff})$.

Since its establishment as a subject, archaeology has itself become fragmented into a large number of subdisciplines or specialities. It was thus noted relatively recently that there are more than 100 different archaeologies with their own designations, including my own specialities "historical archaeology" and "church archaeology" (Rudebeck 2009: 18). But there is undoubtedly room for "a thousand archaeologies" in the future.

Specialisation is encouraged by an academic dynamic, in which positions and capital are sought at the "forefront of research". New perspectives are soon defined as their own specialities and, if possible, as their own subjects, which may generate a return in the form of appointments, money, and prestige. In addition, specialisation is an effective means of attaining knowledge; it may also be necessary as the quantity of methods and data increases. However, specialisation also means that we know more and more about less and less. The great questions, the overview and the syntheses, are impeded or prevented.

The concept of archaeology is still used in philosophy and in other contexts as a metaphor for a particular method. The archaeologist has become a detective looking for hidden clues. Archaeology is associated with depth, excavation, and uncovering what is hidden under the surface, as well as with stratification, the uncertain, fragments, and documentation (e.g. Lowenthal 1985: 251ff; 2015: 401ff; Ebeling \& Altekamp 2004; Holtorf 2005: $16 \mathrm{ff})$.

The passion that the physician Sigmund Freud had for archaeology and antiquity has attracted considerable attention, and his psychoanalysis has been compared with an archaeological excavation (Møller 1994; Thomas 2004: 149ff; Kuusamo 2011). Above Freud's famous divan in Vienna there hung a gouache, a picture of Abu Simbel from 1907 (Pollock 2006: 2 with fig. 1.1, 8f).

Another famous example is the philosopher and historian of ideas Michel Foucault, who called his own method for bringing out 
knowledge hidden in the archives "archaeological" (cf. Foucault 1966 (French); 1971 (English); 1969 (French); 1972 (English)).

Metaphorical archaeology is tempting with its undisciplined freedom. But my method is perhaps the opposite of archaeology. Neither non-archaeology nor pseudo-archaeology, it is a kind of anti-archaeology. Because whereas archaeology digs deep and works with materiality in a long temporal perspective, I will look up from the ground to the sky in an attempt to form an overview, working with library books and the more transient world of the computer screen.

My investigation may be an example of archaeosophy, archaeology, historical archaeology, glocal archaeology, canonical or critical heritage studies, or some seventh pursuit. But in actual fact, academic designations and divisions into subjects are uninteresting when we think and write: it must be left to others, or to the future, to bring order to a writer's identities, perspectives, and investigations (cf. Febvre 1949 (French): 231f; 1973 (English): 31; Foucault 1969: 28 (French); 1972: 17 (English)). As a didactic device, I have nonetheless chosen to assign professional labels to individuals mentioned in this text, while their national identities have been deliberately omitted.

If you follow your curiosity and conscience wherever that path may lead; formulate questions and seek answers irrespective of whether they belong to this or that discipline, culture, or tradition; freely seek enlightenment in the conviction that knowledge can bring about change; and try to cross the dividing line between knowledge, aesthetics, and ethics, as well as the dividing line between "is" and "ought" - well, then you are by necessity an engaged - and troublesome - amateur (cf. Said 1994).

The purpose of Heritopia: World Heritage and modernity is to try to understand and explain the importance of the past in the present by starting out from glocal examples of heritage, namely World Heritage sites. The background is my own and many others' amazement in the face of a much-debated upturn that is observable across the field of history, memory, and heritage, albeit my inquiry chooses to focus on heritage and, within that area, on World Heritage sites in particular.

In methodological terms, World Heritage sites will be included in the inquiry both as individual examples and as a statistical population. Abu Simbel will turn up regularly. But otherwise attention is generally drawn to what is different, marginal, or border-crossing, which may indirectly shed light on normality: World Heritage sites 
that are controversial, threatened, vandalised, or have simply been removed from the List; places that could be expected to be World Heritage sites but are nonetheless not on the List; and countries that still do not have any World Heritage, or have not even ratified the Convention.

To understand and explain the importance of the past, it is, in my view, necessary to bridge not only the gap between the two cultures of heritage, but also other trenches between different cultures, perspectives, and academic subjects that split up the field. Consequently, references will be made both to academic texts and to literary and cinematic fiction, to sciences, humanities, and social sciences - and use will be made of both qualitative interpretation and quantitative analysis. Moreover, I consider that heritage and World Heritage cannot be examined in isolation from the more general development of society. To be able to understand and explain heritage and World Heritage, we need to understand and explain present-day developments.

The main question addressed in this book may be briefly formulated as follows: What is the relationship between World Heritage and modernity? In the light of the paradoxes of heritage, a number of subsidiary questions can then be formulated: Is preservation of World Heritage for the future possible? Is World Heritage changed when efforts are made to protect and preserve it? Is the protection and preservation of World Heritage offset by more destruction at other places? Are threats of destruction a precondition for World Heritage? Is World Heritage contrary to modernity and a part of it at the same time? Is World Heritage promoted by both more and less modernity? Is World Heritage border-crossing?

The present chapter, Chapter 1, "The past is everywhere", constitutes an introduction which presents the field of problems with its paradoxes, taking Abu Simbel as its starting point. Chapter 2, "Truth, beauty, and goodness", considers reasons, motives, and values involved in preserving the past. Chapter 3, "Chronic nostalgia", discusses (mis)use of the past and crisis theories, all of which have one feature in common: they regard interest in the past as a compensation for phenomena in the present. Chapter 4, "The faces of modernity", analyses central concepts such as time, change, permanence, progress, and decay, and it presents a new perspective on modernity. Chapter 5, "Heritage in the present", examines the growth of heritage as a concept and a field, and it looks at how the concept has expanded. Chapter 6, "Destination World Heritage", examines the World Heritage Convention as a modern innovation; 
the chapter discusses the list of outstanding and universal World Heritage sites as an example of canonisation and also as a reaction against an ongoing inflation of heritage. Chapter 7, "World Heritage and modernity", introduces the concept of Heritopia, and returns to Abu Simbel and other World Heritage sites in an attempt to understand and explain the seven paradoxes listed near the beginning of this introductory chapter. 


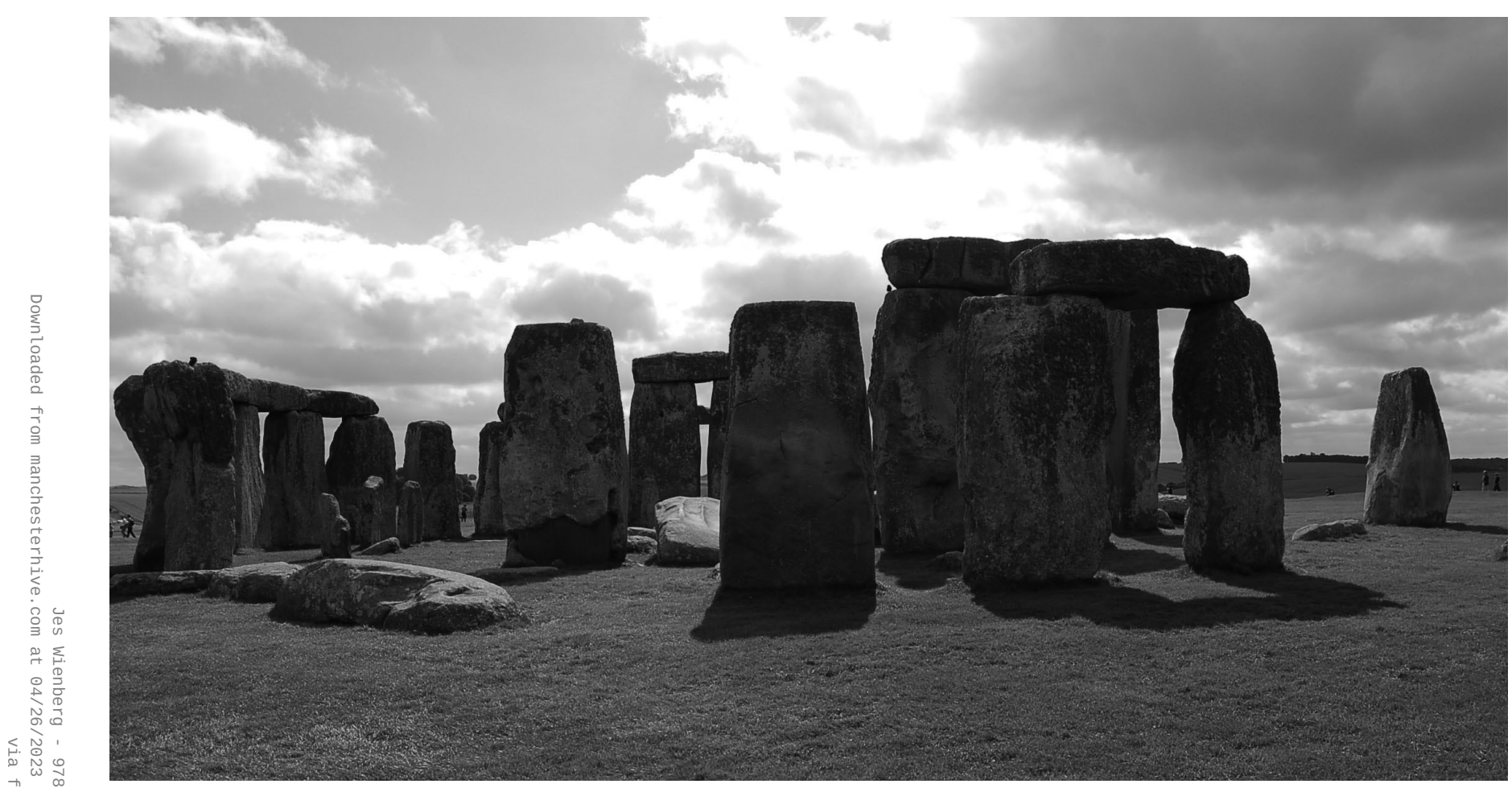

Figure 2 Stonehenge. Photo @ Lars Larsson, 2008. 